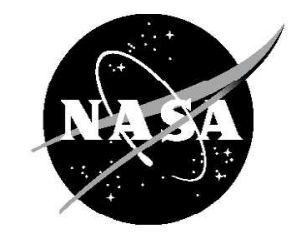

\title{
Active "Fail-Safe" Micro-Array Flow Control for Advanced Embedded Propulsion Systems
}

Bernhard H. Anderson

Glenn Research Center, Cleveland, Ohio

James L. Mace and Mori Mani

The Boeing Company, St. Louis, Missouri 


\section{NASA STI Program . . . in Profile}

Since its founding, NASA has been dedicated to the advancement of aeronautics and space science. The NASA Scientific and Technical Information (STI) program plays a key part in helping NASA maintain this important role.

The NASA STI Program operates under the auspices of the Agency Chief Information Officer. It collects, organizes, provides for archiving, and disseminates NASA's STI. The NASA STI program provides access to the NASA Aeronautics and Space Database and its public interface, the NASA Technical Reports Server, thus providing one of the largest collections of aeronautical and space science STI in the world. Results are published in both non-NASA channels and by NASA in the NASA STI Report Series, which includes the following report types:

- TECHNICAL PUBLICATION. Reports of completed research or a major significant phase of research that present the results of NASA programs and include extensive data or theoretical analysis. Includes compilations of significant scientific and technical data and information deemed to be of continuing reference value. NASA counterpart of peer-reviewed formal professional papers but has less stringent limitations on manuscript length and extent of graphic presentations.

- TECHNICAL MEMORANDUM. Scientific and technical findings that are preliminary or of specialized interest, e.g., quick release reports, working papers, and bibliographies that contain minimal annotation. Does not contain extensive analysis.

- CONTRACTOR REPORT. Scientific and technical findings by NASA-sponsored contractors and grantees.
- CONFERENCE PUBLICATION. Collected papers from scientific and technical conferences, symposia, seminars, or other meetings sponsored or cosponsored by NASA.

- SPECIAL PUBLICATION. Scientific, technical, or historical information from NASA programs, projects, and missions, often concerned with subjects having substantial public interest.

- TECHNICAL TRANSLATION. Englishlanguage translations of foreign scientific and technical material pertinent to NASA's mission.

Specialized services also include creating custom thesauri, building customized databases, organizing and publishing research results.

For more information about the NASA STI program, see the following:

- Access the NASA STI program home page at http://www.sti.nasa.gov

- E-mail your question via the Internet to help@ sti.nasa.gov

- Fax your question to the NASA STI Help Desk at $443-757-5803$

- Telephone the NASA STI Help Desk at 443-757-5802

- Write to: NASA Center for AeroSpace Information (CASI) 7115 Standard Drive Hanover, MD 21076-1320 


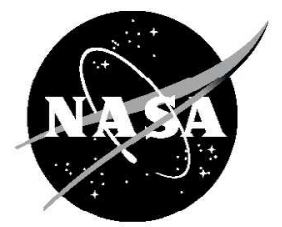

\section{Active "Fail-Safe" Micro-Array Flow Control for Advanced Embedded Propulsion Systems}

Bernhard H. Anderson

Glenn Research Center, Cleveland, Ohio

James L. Mace and Mori Mani

The Boeing Company, St. Louis, Missouri

Prepared for the

47th Aerospace Sciences Meeting

sponsored by the American Institute of Aeronautics and Astronautics

Orlando, Florida, January 5-8, 2009

National Aeronautics and

Space Administration

Glenn Research Center

Cleveland, Ohio 44135 
This report is a formal draft or working paper, intended to solicit comments and ideas from a technical peer group.

This report contains preliminary findings, subject to revision as analysis proceeds.

This work was sponsored by the Fundamental Aeronautics Program at the NASA Glenn Research Center.

Level of Review: This material has been technically reviewed by technical management.

Available from

NASA Center for Aerospace Information 7115 Standard Drive

Hanover, MD 21076-1320
National Technical Information Service 5285 Port Royal Road Springfield, VA 22161

Available electronically at http://gltrs.grc.nasa.gov 


\title{
Active "Fail Safe" Micro-Array Flow Control for Advanced Embedded Propulsion Systems
}

\author{
Bernhard H. Anderson \\ National Aeronautics and Space Administration \\ Glenn Research Center \\ Cleveland, Ohio 44135 \\ James L. Mace and Mori Mani \\ The Boeing Company \\ St. Louis, Missouri 63042
}

\begin{abstract}
The primary objective of this research effort was to develop and analytically demonstrate enhanced first generation active "fail-safe" hybrid flow-control techniques to simultaneously manage the boundary layer on the vehicle fore-body and to control the secondary flow generated within modern serpentine or embedded inlet S-duct configurations. The enhanced first-generation technique focused on both micro-vanes and micro-ramps highly-integrated with micro-jets to provide nonlinear augmentation for the "strength" or effectiveness of highly-integrated flow control systems. The study focused on the micro-jet mass flow ratio (Wjet/Waip) range from 0.10 to 0.30 percent and jet total pressure ratios (Pjet/Po) from 1.0 to 3.0. The engine bleed airflow range under study represents about a 10 fold decrease in micro-jet airflow than previously required. Therefore, by pre-conditioning, or injecting a very small amount of high-pressure jet flow into the vortex generated by the micro-vane and/or micro-ramp, active flow control is achieved and substantial augmentation of the controlling flow is realized.
\end{abstract}

\section{Nomenclature}

Ai Coefficients in Regression Model, Equation (4)

AIP Aerodynamic Interface Plane

$\mathrm{Au} \quad$ Boundary Layer Augmentation Parameter, Equation (2)

BLI Boundary Layer Ingestion

Bp Micro-Jet Pitch Angle

Bs Micro-Jet Skew Angle

c Micro-Actuator Chord Length

CCF Central Composite Face-Centered

CFD Computational Fluid Dynamics

df Degrees of Freedom in Error

DOE Design of Experiments

h Micro-Actuator Height

K Transverse to Streamwise Kinetic Energy Ratio, Equation (1)

Htr Boundary Layer Transformed Form Factor

PFAVE Boundary Layer Total Pressure Recovery

Pjet Micro-Jet Total Pressure

Po Free Stream Total Pressure

RSM Response Surface Methodology

$\mathrm{Rn} \quad$ Error Term in Regression Model, Equation (4)

S Transverse Spacing

Sy.x Standard Deviation

U Streamwise Velocity 


$\begin{array}{ll}\text { V } & \text { Velocity in Normal Direction } \\ \text { W } & \text { Velocity in Transverse Direction } \\ \text { Wjet } & \text { Micro-Jet Mass Flow } \\ \text { X } & \text { Streamwise Distance } \\ \text { Xaip } & \text { Reference (AIP) Station Streamwise Location } \\ \text { Xi } & \text { Factor Variable } \\ \text { Yi } & \text { Response Variable } \\ \text { Waip } & \text { Mass Flow at AIP (Reference) Station } \\ \Delta X j e t & \text { Streamwise Location of Micro-Jet } \\ \Delta \text { Yjet } & \text { Transverse Location on Micro-Jet } \\ \delta^{*} & \text { Boundary Layer Displacement Thickness } \\ \theta & \text { Boundary Layer Momentum Thickness } \\ \rho & \text { Density }\end{array}$

\section{Introduction}

Modern inlet/airframe design concepts have moved toward top-mounted embedded-propulsion systems using variations on "Boundary Layer Ingestion" (BLI) inlet concepts. The reason for this change is to reduce the overall aircraft drag, minimize the emitted noise and improve survivability. However, these changes in design approach require development of advanced boundary-layer techniques to manage the inlet capture mass flow and to control the induced secondary flows generated within the highly conformal serpentine or embedded S-duct geometries. There are basically two approaches to managing the boundary layers for such inlet systems, namely (1) "preconditioning" the boundary layer to negotiate adverse pressure gradients on the fore-body and thus improve the inlet capture mass flow, and (2) "secondary flow control" to prevent or minimize the formation of inlet secondary flow and thereby reduce engine-face total-pressure distortion. Both of these techniques must be designed and used in conjunction with each other to manage the boundary layer in modern inlet/airframe concepts.

Previous research on inlet flow-control systems, spearheaded by the NASA Glenn Research Center (GRC) (Refs. 1 to 3), has led to highly successful passive and active flow-control systems to manage the secondary flow generated within S-duct and serpentine inlet configurations. Each system, whether passive or active, has positive features as well as operational limitations. The passive flow control systems are not fully active in that each actuator can not be individually managed. However, they are "fail-safe" and can be designed and optimized to operate successfully over a range of inlet operating conditions using Robust or Taguchi DOE Design Methodologies (Refs. 4 to 7). Fully-active flow-control systems using micro-jet actuation, however, can individually manage to control flow. However, they are not inherently "fail safe", (i.e., the fail safe feature is not designed into the actuator itself). Also, they require 1.0 to 3.0 percent of the engine bleed airflow to operate successfully. This is a large amount airflow which penalizes engine performance.

Active hybrid flow-control research, also spearheaded by NASA GRC, has led to a first generation hybrid flow-control system. The intent of this research was to combine the "fail-safe" features of passive micro-vane control with the active capability of micro-jet flow control. This first generation hybrid flowcontrol system was designed and tested by the Boeing Company under funding from the Air Force's "Versatile Affordable Advanced Turbine Engine" (VAATE) program. This system is comprised of passive micro-vanes loosely integrated with the micro-jets located well downstream of the micro-vanes in a serpentine diffuser. The technology meets design pressure recovery and distortion goals using from 1.0 to 2.0 percent of engine airflow for the micro-jet flow control.

Several beneficial improvements over the first generation system have been postulated. First, there is a desire to develop an enhanced first-generation hybrid flow-control system which uses significantly less engine airflow. Second, there is a desire to develop a more-robust hybrid flow-control system by replacing the micro-vanes with micro-ramps which are less-prone to damage during operation or 
maintenance actions. Passive micro-ramp flow control has been used to successfully manage the shock/wave boundary-layer interaction for supersonic inlets (Ref. 8).

The issue of active "fail-safe" micro-array flow control, where the fail-safe feature is built into the individual actuators, has not received attention from the flow-control research community. However, "fail safe" flow-control always surfaces whenever flow-control is applied to a flight system. While micro-jet flow control has been applied successfully to compact inlet systems to manage secondary flow, it is not inherently "fail-safe". In addition these flow control systems require 1.0 to 3.0 percent of the engine airflow to be effective and this represents a large engine performance penalty.

Therefore, the purpose of the collaborative research study is to develop an enhanced first generation hybrid flow-control system whose actuators are inherently "fail safe" and use substantially less engine airflow than previously needed. The NASA Technology Serial No. for hybrid micro-vane/ramp actuators introduced in this paper is LEW-18322-1. The enhanced first-generation system will focus on both microvanes and micro-ramps highly-integrated with micro-jets to provide nonlinear augmentation for the "strength" or effectiveness of the flow control systems. The study will focus on the engine bleed airflow (Wjet/Waip) range from 0.10 to 0.30 percent and jet total pressure ratios (Pjet/Po) range from 1.0 to 3.0. The engine bleed airflow range under study therefore represents about a 10 fold decrease in the required micro-jet airflow than previously needed. Therefore, by pre-conditioning, or injecting a small amount of high-pressure jet flow into the vortex generated by the micro-vane and/or micro-ramp, active flow control is achieved and substantial augmentation of the controlling flow is realized.

\section{Results and Discussion}

\section{Design Approach to Optimal Micro-Array Hybrid Flow Control}

The basic problem of experimental and CFD design is deciding what approach, or arrangement of test cases to be "run", will best reveal aspects of the situation of interest. For that reason, the overall objectives of the study become very important. In the present study, three objectives were considered important, namely (1) develop response surfaces that enable the design of optimal hybrid actuator configurations which meet the mission needs, (2) establish the range of possible augmentation amounts that are available for use in the practical applications of hybrid actuators, and (3) determine the design guidelines for "synthetic jet" actuators which may be a practical replacement for steady micro-jet actuators.

One of the most difficult tasks in the design of a flow control installation for optimal operation is arriving at the geometric placement, arrangement, number, size and orientation of the effector devices within the inlet duct to achieve optimal performance. These actuator devices can be either mechanical or fluidic. In this study, however, the design task is further complicated by the fact that micro-vanes and micro-ramps are combined with micro-jets to form a single actuator system. Hence, the number of factor variables is dramatically increased and the number of possible design cases to be studied enlarged prohibitively. The design task is further complicated by the existence of hard-to-control factors which affect actuator performance (i.e., the mission variables).

The mission variables are the flight conditions, the engine corrected air flow, angle-of-incidence and angle-of-yaw. While the aerodynamicist does not know how the pilot is ultimately going to fly the aircraft, it is known how the mission variables affect inlet performance under wind tunnel conditions. Traditionally, tolerance or robustness to the mission variables was accomplished only after the parameter design was completed, usually by accepting whatever off-design performance was delivered by the newly designed control system. Numerical optimization procedures that have been successful with some aerodynamics problems give little assistance to designing robust flow control since they are point-design procedures, usually with only one decision parameter. However, there is a branch of statistical Design-ofExperiments (DOE) methodology which integrates both traditional Response Surface Methods (Ref. 9) (RSM) and robustness considerations (Ref. 10) into a single optimization procedure (Refs. 4 and 5). It presents new potential for further reduction of Total Quality Cost over the traditional design approach. 


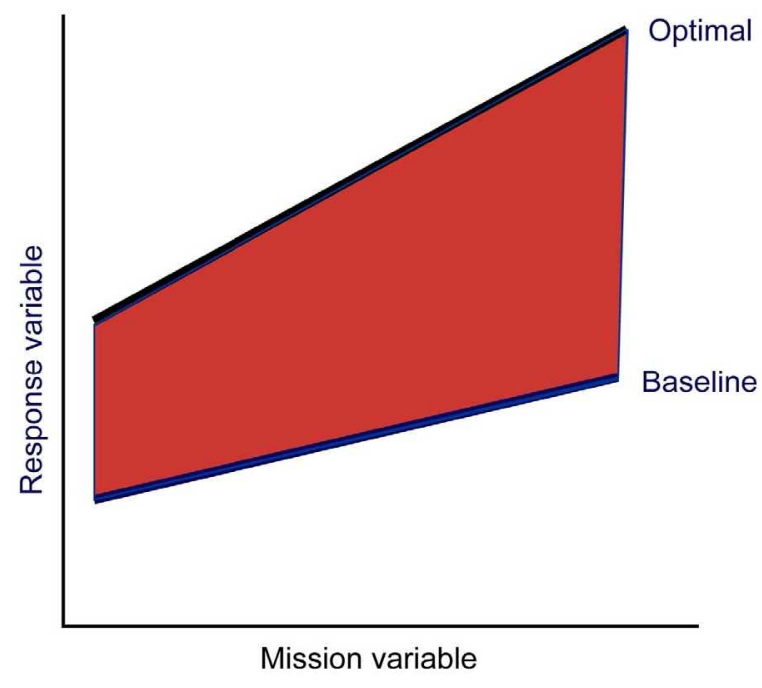

Figure 1.-Standard flow-control domain.

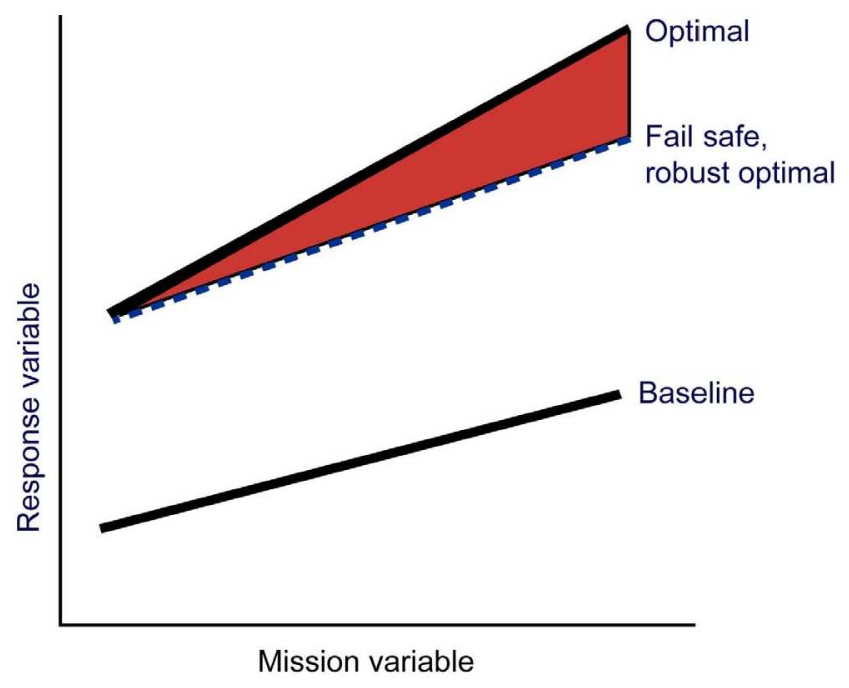

Figure 2.-Hybrid flow-control domain.

The traditional approach to flow control is illustrated in Figure 1, which shows the relationship between the mission variables (i.e., the flight conditions, engine corrected air flow, angle-of-incidence and angle-of-yaw etc.), and the response variables (i.e., inlet total pressure recovery and distortion), and the metrics that affect high cycle fatigue of engine blades. The objective of flow control, therefore, is to change the behavior of the inlet system from its baseline performance (without flow control) to the optimal level of performance. The optimal performance over the flight envelope can never be entirely realized with a passive system. However, optimal inlet performance can be fully realized with a fully active system because the flow control system can be adjusted to the changing flight envelope. However, experience has shown that an active flow control system, such as micro-jet actuators, has two major disadvantages, namely, (1) they are not inherently "fail-safe" and (2) they require engine bleed air flow between Wjet/Waip $=1.0$ to 3.0 percent to operate successfully. To overcome these disadvantages, active "fail-safe" hybrid flow control systems were initiated is illustrated in Figure 2.The object of the active part of hybrid systems, therefore, is to adjust the performance from the robust optimal level, i.e., the "fail safe operating level, over the flight envelope, to the optimal performance level. By designing the hybrid flow control system to operate in a "nonlinear" fashion, large augmentation of the flow control system can be realized with small amounts of engine bleed air flow (i.e., between Wjet/Waip $=0.1$ to 0.3 percent). Figures 3 and 4 illustrate the geometric arrangement of such nonlinear hybrid flow control systems.

\section{The Design-of-Experiment (DOE) Strategy}

Data for the hybrid flow control actuators that are, shown in Figures 3 and 4, was obtained using CFD analysis. The actuators were modeled in a tunnel geometry corresponding to the 15 by $15 \mathrm{~cm}$. Supersonic Wind Tunnel at NASA GRC. The tunnel Mach number was set at 0.5 , with a tunnel total pressure of $2117.0 \mathrm{psf}$ and total temperature of $517.0^{\circ} \mathrm{R}$. The grid topology contained only one actuator with symmetric boundary conditions applied to the side planes located at the spacing (s) assigned to the DOE variables that were held constant, Table 1 . Other factors that were held constant in the analysis were micro-actuator height (h), set at $3 \mathrm{~mm}$. for micro-vanes and $5 \mathrm{~mm}$ for micro-ramps, the micro-actuator chord length (c), the micro-actuator pitch angle $(\mathrm{Bp})$, the stream-wise location of the micro-jets relative to the actuators $(\Delta \mathrm{Xjet})$, the transverse location on the micro-jets relative to the actuators $(\Delta \mathrm{Yjet})$, and the micro-jet skew angle (Bs). The values of the factor variable that were held constant were determined through a DOE screening study (Ref. 9). The purpose of the screening study was to determine the best location and orientation of the micro-jets relative to the micro-actuators to insure control augmentation 
and to set the range of the factor variables which should be studied in the DOE itself. In the screening DOE study, there were actually 10 independent factor (design) variables considered. Using a "Main Effects" DOE strategy, there were 11 CFD cases run in the screening process. The results of the screening study provided the best overall location and orientation of the micro-jet relative to the micro-vane/ramp actuator.



(a)

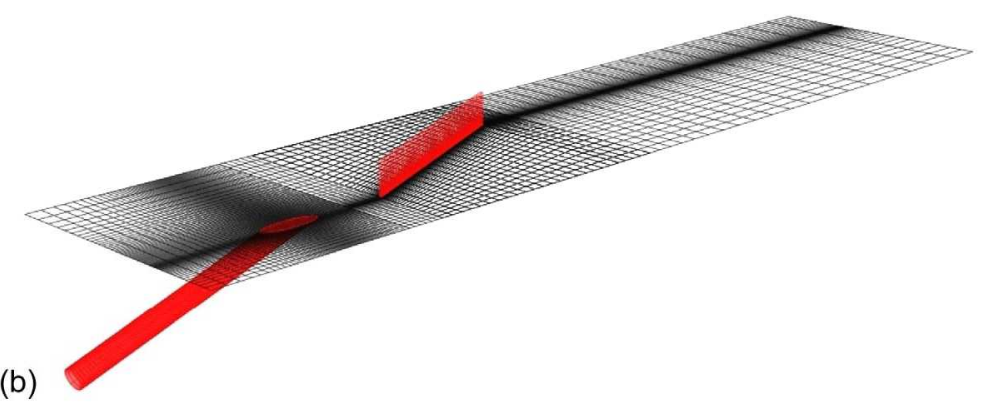

Figure 3.-Schematic diagram showing micro-vane actuator configuration. (a) Baseline. (b) Hybrid.

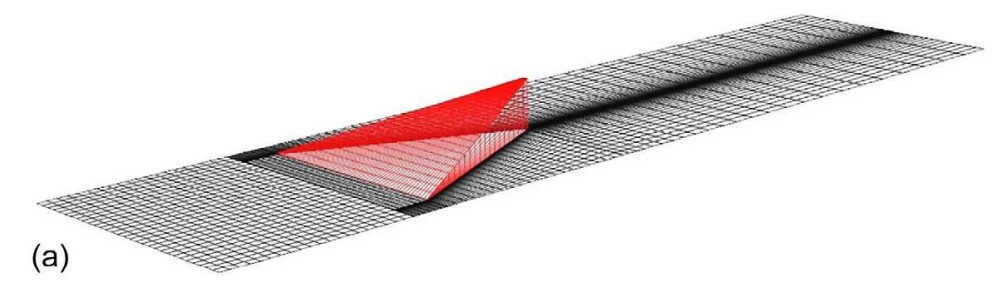

(b)

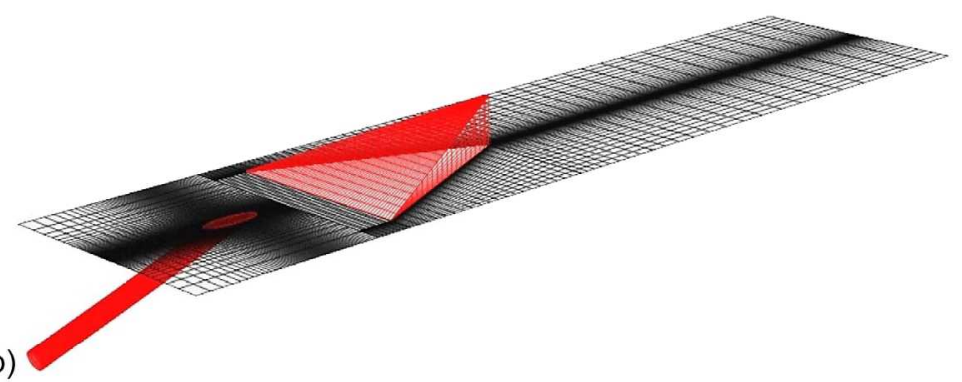

Figure 4.-Schematic diagram showing micro-ramp actuator configuration. (a) Baseline. (b) Hybrid. 
TABLE 1.-HYBRID MICRO-VANE/RAMP ACTUATOR VARIABLES HELD CONSTANT

\begin{tabular}{|c|c|}
\hline Variable & Value \\
\hline Transverse Spacing (mm), s & 25.0 \\
\hline Micro-Vane/Ramp Height (mm), h & $3.0 / 5.0$ \\
\hline Micro-Vane/Ramp Chord Length (mm), c & 24.0 \\
\hline Micro-Vane/Ramp Angle of Incidence, (degs) Ap & 24.0 \\
\hline Streamwise Location of Micro-Jet (mm), $\Delta$ Xjet (1) & 10.0 \\
\hline Spanwise Location of Micro-Jet (mm), $\Delta$ Yjet (1) & 0.0 \\
\hline Micro-Jet Skew Angle, (degs). Bs & 0.0 \\
\hline
\end{tabular}

(1) The position of the micro-jet is measure upstream relative to the centerline location of the micro-vane/ramp leading edge.

The design variables (factors) considered that form the DOE study are presented in Table 2, and include the micro-jet pitch angle (Bp), the micro-jet mass flow ratio (Wjet/Waip), and the micro-jet total pressure ratio (Pjet/Po). The DOE study focused on the engine bleed airflow (Wjet/Waip) range from 0.10 to 0.30 percent and jet total pressure ratios (Pjet/Po) from 1.0 to 3.0. The micro-jet mass flow ratio range under study therefore represents about a 10 fold decrease in micro-jet airflow than previously required. The microjet pitch angle (Bp) was varied from $20^{\circ}$ to $40^{\circ}$ relative to the tunnel- floor surface.

TABLE 2.-HYBRID MICRO-VANE/RAMP ACTUATOR FACTORS WHICH ESTABLISH THE DOE DESIGN MATRIX

\begin{tabular}{|c|c|}
\hline Variable & Range \\
\hline Micro-Jet Pitch Angle, (degs). Bp & $20.0-40.0$ \\
\hline Micro-Jet Mass Flow Ratio, Wjet/Waip & $0.10 \%-0.30 \%$ \\
\hline Micro-Jet Total Pressure Ratio, Pjet/Po & $1.0-3.0$ \\
\hline
\end{tabular}

The response variables (design metrics) considered for this study, listed in Table 3, were the boundary-layer total-pressure recovery (PFAVE), the compressible boundary-layer displacement thickness $\left(\delta^{*}\right)$, the compressible boundary-layer momentum thickness $(\theta)$, and boundary layer transformed form factor (Htr). The transformed form factor (Htr) was calculated from the incompressible shape factor (Hi) equations, but is often referred to as the transformed form factor since it is applied in the compressible regime. Each of these boundary layer parameters was measured at the AIP, or reference measurement station located at a streamwise location (X) of $4.0 \mathrm{~cm}$. In addition to the boundary layer parameters two additional metrics were measured in this study. These were the percent cross-stream kinetic energy ratio $(\% \mathrm{~K})$ and the percent augmentation parameter $(\% \mathrm{Au})$. Both of these response variables were measured at the trailing edge of the micro-vane $/ \mathrm{ramp}$, (located at $\mathrm{X}=-11.5 \mathrm{~cm}$ ). The percent area-weighted cross-stream kinetic energy-ratio $(\% \mathrm{~K})$ was defined as

$$
\% \mathrm{~K}=100.0 *\left(\rho \mathrm{V}^{2}+\rho \mathrm{W}^{2}\right) / \rho \mathrm{U}^{2}
$$

where $\rho$ is the density, $\mathrm{V}$ and $\mathrm{W}$ the cross-stream velocity components, and $\mathrm{U}$ is the streamwise velocity. The area-weighted percent-augmentation parameter (\%Au) was defined as

$$
\% \mathrm{Au}(\text { hybrid })=100.0 *(\mathrm{~K}(\text { hybrid })-\mathrm{K}(\text { vane } / \mathrm{ramp})) / \mathrm{K}(\mathrm{van} / \mathrm{ramp})
$$


TABLE 3.-HYBRID MICRO-VANE/RAMP ACTUATOR

DOE DESIGN RESPONSE VARIABLES

\begin{tabular}{|c|c|}
\hline Response Variable & Nomenclature \\
\hline Boundary Layer Total Pressure Recovery & PFAVE (1) \\
\hline Compressible Displacement Thickness & $\boldsymbol{\delta}^{\star(1)}$ \\
\hline Compressible Momentum Thickness & $\boldsymbol{\theta}^{(1)}$ \\
\hline Transformed Form Factor & $\mathrm{Htr}^{(1)}$ \\
\hline Percent Cross-Stream Kinetic Energy Ratio & \%K $^{(2)}$ \\
\hline Augmentation Parameter & Au (2) $^{(2)}$ \\
\hline
\end{tabular}

(1) Measured at the AIP (Reference) plane, $X=4.0(\mathrm{~cm})$

(2) Measured at the micro-array trailing edge, $X=-11.5(\mathrm{~cm})$

Therefore, the percent augmentation parameter (\%Au) measures the change in the cross-stream kineticenergy ratio as a result of the combined micro-jet micro-vane/ramp hybrid actuator configuration. In order to measure the nonlinear aspect of micro-jet micro-vane/ramp combination, an area-weighted micro-jet percent augmentation parameter $(\% \mathrm{Au})$ was defined as

$$
\% \mathrm{Au}(\text { micro }- \text { jet })=100.0 * \mathrm{~K}(\text { micro }- \text { jet }) / \mathrm{K}(\operatorname{van} / \text { ramp })
$$

The DOE strategy selected for this study was a Central Composite Face-Centered (CCF) design as shown in Tables 4 and 5. This strategy resulted in two sets of 15 unique CFD analysis cases, one set for the hybrid micro-vane, Table 4, and another for the hybrid micro-ramp actuator, Table 5. This particular DOE design, like most DOE strategies, varied more than one factor at a time. Further, this layout of 15 cases permitted the estimation of both linear and curvilinear effects as well as two-factor interactive or synergistic effects among the factor variables. These two DOE cases are called a composite design because the layout of cases is composed of a factorial part and a quadratic part. The full factorial part is composed of the $2^{3}$ or 8 cases. The remainder of the cases is the quadratic part of the DOE. All together, there are 15 cases in a CCF design with three factor variables. This layout represents the smallest number of DOE cases that allow for the evaluation of the linear and curvilinear effects as well as all the twofactor or first-order interactions.

One critical aspect of Response Surface Methodologies (Ref. 9) (RSM) is its ability to identify, prioritize, and examine statistical interactions among the factors (design) variables. Knowledge of these statistical interactions is critical for achieving optimal micro-array designs. A statistical interaction exists between two independent factor variables $\mathrm{X} 1$ and $\mathrm{X} 2$ when the effect of $\mathrm{X} 1$ on response variable $\mathrm{Yi}$ is affected by the value of $\mathrm{X} 2$. In other words, the effect of factor $\mathrm{X} 1$ on response $\mathrm{Yi}$ is not unique, but changes as a function of X2. This type of behavior is often called a synergistic effect and its understanding is very critical in the optimization process of hybrid micro-array flow control devices.

Each of the 2x15 cases, representing the DOE design for the hybrid micro-vane actuator, Figure 3(b), and hybrid micro-ramp actuator, Figure 4(b), were run with the Reynolds-averaged Navier-Stokes WIND code (Refs. 11 and 12). In the present study, the individual hybrid and micro-vane/ramp actuators (including the micro-jet) were incorporated into the grid topology, and are shown in Figures 3(b) to 4(b). The complete grid was composed of six blocks; an upstream block, two working blocks, two downstream blocks, and one block containing the grid for the micro-jet actuator. Since the need existed to economize because of the large number of cases to be run, and to guarantee proper grid resolution in the neighborhood of the micro-actuators, only a single hybrid micro-vane or hybrid micro-ramp geometry was considered. Symmetry boundary conditions were then applied to the grid side walls, and viscous-wall boundary conditions were applied to the shock-generator and top-wall surfaces. The CFD cases were run with a grid containing 831,726 mesh points for the hybrid micro-vane actuator cases, and 1,070,195 mesh points for the hybrid micro-ramp actuator cases. See Figures 3(b) and 4(b) for the grid topology. 
TABLE 4.-HYBRID MICRO-VANE CCF DESIGN MATRIX WITH PERFORMANCE RESULTS

\begin{tabular}{|c|c|c|c|c|c|c|c|c|c|}
\hline Config. & Bjet & Wjet/Waip & Pjet/Po & PFAVE & $\delta^{*}(\mathbf{c m})$ & $\theta(\mathbf{c m})$ & Htr & $\%$ K & $\%$ Au \\
\hline hvg200 & - & - & - & 0.956 & 0.247 & 0.175 & 1.293 & $2.677 \%$ & NA \\
\hline hvg201 & 20.0 & $0.10 \%$ & 1.0 & 0.957 & 0.254 & 0.181 & 1.289 & $2.539 \%$ & $-5.2 \%$ \\
\hline hvg202 & 60.0 & $0.10 \%$ & 1.0 & 0.957 & 0.259 & 0.184 & 1.298 & $2.579 \%$ & $-3.7 \%$ \\
\hline hvg203 & 20.0 & $0.30 \%$ & 1.0 & 0.958 & 0.251 & 0.180 & 1.280 & $2.711 \%$ & $1.3 \%$ \\
\hline hvg204 & 60.0 & $0.30 \%$ & 1.0 & 0.956 & 0.264 & 0.186 & 1.298 & $2.703 \%$ & $0.1 \%$ \\
\hline hvg205 & 20.0 & $0.10 \%$ & 3.0 & 0.960 & 0.249 & 0.178 & 1.266 & $2.642 \%$ & $-1.3 \%$ \\
\hline hvg206 & 60.0 & $0.10 \%$ & 3.0 & 0.958 & 0.243 & 0.175 & 1.283 & $2.849 \%$ & $6.5 \%$ \\
\hline hvg207 & 20.0 & $0.30 \%$ & 3.0 & 0.967 & 0.190 & 0.144 & 1.316 & $10.913 \%$ & $307.1 \%$ \\
\hline hvg208 & 60.0 & $0.30 \%$ & 3.0 & 0.962 & 0.222 & 0.163 & 1.258 & $3.883 \%$ & $54.9 \%$ \\
\hline hvg209 & 20.0 & $0.20 \%$ & 2.0 & 0.962 & 0.217 & 0.160 & 1.253 & $5.189 \%$ & $93.8 \%$ \\
\hline hvg210 & 60.0 & $0.20 \%$ & 2.0 & 0.958 & 0.246 & 0.177 & 1.281 & $2.979 \%$ & $11.3 \%$ \\
\hline hvg211 & 40.0 & $0.10 \%$ & 2.0 & 0.958 & 0.244 & 0.175 & 1.282 & $2.769 \%$ & $3.4 \%$ \\
\hline hvg212 & 40.0 & $0.30 \%$ & 2.0 & 0.961 & 0.225 & 0.165 & 1.259 & $4.816 \%$ & $79.9 \%$ \\
\hline hvg213 & 40.0 & $0.20 \%$ & 1.0 & 0.957 & 0.258 & 0.183 & 1.402 & $2.658 \%$ & $0.7 \%$ \\
\hline hvg214 & 40.0 & $0.20 \%$ & 3.0 & 0.962 & 0.220 & 0.162 & 1.254 & $3.735 \%$ & $39.5 \%$ \\
\hline hvg215 & 40.0 & $0.20 \%$ & 2.0 & 0.960 & 0.235 & 0.171 & 1.272 & $2.961 \%$ & $10.6 \%$ \\
\hline
\end{tabular}

TABLE 5.-HYBRID MICRO-RAMP CCF DESIGN MATRIX WITH PERFORMANCE RESULTS

\begin{tabular}{|c|c|c|c|c|c|c|c|c|c|}
\hline Config. & Bjet & WjetWaip & Pjet/Po & PFAVE & $\delta^{*}(\mathrm{~cm})$ & $\theta(\mathrm{cm})$ & Htr & $\%$ K & \%Au \\
\hline srm200 & & - & - & 0.960 & 0.235 & 0.172 & 1.257 & $6.475 \%$ & NA \\
\hline srm201 & 20.0 & $0.10 \%$ & 1.0 & 0.960 & 0.236 & 0.174 & 1.252 & $6.132 \%$ & $-5.3 \%$ \\
\hline srm202 & 60.0 & $0.10 \%$ & 1.0 & 0.963 & 0.215 & 0.160 & 1.238 & $6.390 \%$ & $-1.3 \%$ \\
\hline srm203 & 20.0 & $0.30 \%$ & 1.0 & 0.965 & 0.203 & 0.152 & 1.239 & $6.407 \%$ & $-1.1 \%$ \\
\hline srm204 & 60.0 & $0.30 \%$ & 1.0 & 0.962 & 0.220 & 0.164 & 1.238 & $6.476 \%$ & $0.0 \%$ \\
\hline srm205 & 20.0 & $0.10 \%$ & 3.0 & 0.966 & 0.198 & 0.149 & 1.227 & $10.139 \%$ & $56.6 \%$ \\
\hline srm206 & 60.0 & $0.10 \%$ & 3.0 & 0.965 & 0.202 & 0.153 & 1.223 & $6.579 \%$ & $1.6 \%$ \\
\hline srm207 & 20.0 & $0.30 \%$ & 3.0 & 0.971 & 0.156 & 0.118 & 1.222 & $10.181 \%$ & $57.2 \%$ \\
\hline srm208 & 60.0 & $0.30 \%$ & 3.0 & 0.970 & 0.188 & 0.144 & 1.207 & $6.490 \%$ & $0.2 \%$ \\
\hline srm209 & 20.0 & $0.20 \%$ & 2.0 & 0.967 & 0.187 & 0.142 & 1.223 & $11.070 \%$ & $71.0 \%$ \\
\hline srm210 & 60.0 & $0.20 \%$ & 2.0 & 0.965 & 0.205 & 0.155 & 1.225 & $6.700 \%$ & $8.1 \%$ \\
\hline srm211 & 40.0 & $0.10 \%$ & 2.0 & 0.965 & 0.206 & 0.155 & 1.230 & $6.603 \%$ & $2.0 \%$ \\
\hline srm212 & 40.0 & $0.30 \%$ & 2.0 & 0.967 & 0.190 & 0.145 & 1.217 & $6.640 \%$ & $2.4 \%$ \\
\hline srm213 & 40.0 & $0.20 \%$ & 1.0 & 0.963 & 0.216 & 0.161 & 1.237 & $6.540 \%$ & $1.0 \%$ \\
\hline srm214 & 40.0 & $0.20 \%$ & 3.0 & 0.969 & 0.183 & 0.140 & 1.313 & $9.466 \%$ & $46.2 \%$ \\
\hline srm215 & 40.0 & $0.20 \%$ & 2.0 & 0.966 & 0.197 & 0.150 & 1.222 & $6.589 \%$ & $1.8 \%$ \\
\hline
\end{tabular}


The CCF design layout along with the CFD response results is presented in Table (4) for the hybrid micro-vane actuators and Table 5 for the hybrid micro-ramp actuators. Each of the two DOE layouts, like most DOE strategies, varies more than one factor at a time. Further, this DOE design layout of 15 cases permits the estimation of both linear and curvilinear effects as well as interactive or synergistic effects among the DOE factors. The resulting generalized regression model for each of the response variables is of the form

$$
\mathrm{Y}=\sum_{\mathrm{i}=1}^{\mathrm{N}} \mathrm{AiX}_{\mathrm{i}}+\sum_{\mathrm{i}=1}^{\mathrm{N}} \sum_{\mathrm{j}=1}^{\mathrm{N}} \mathrm{Aij}_{\mathrm{ij}} \mathrm{X}_{\mathrm{X}} \mathrm{j}+\sum_{\mathrm{i}=1}^{\mathrm{N}} \mathrm{AiiX}^{2}+\mathrm{Rn}\left(\mathrm{df}, \mathrm{S}_{\mathrm{y} . \mathrm{x}}, \mathrm{X}_{1}, \mathrm{X}_{2}, \ldots . ., \mathrm{XN}_{\mathrm{N}}\right)
$$

The statistically significant transformed coefficients for the regression model describing the percent augmentation parameter $(\% \mathrm{Au})$ are presented in Table 6 for the hybrid micro-vane/ramp actuators. These terms were obtained by performing a backwards elimination and retaining only those terms that had pvalues less 0.10 . This insures that the statistically significant transformed regression coefficients $\left(A_{i}{ }^{\prime} \mathrm{s}\right)$ listed in Table 6 have a 90 percent confidence level or greater. The generalized regression model, Equation (4), is based on the Taylor series expansion, and therefore contains an error term, $R n\left(d f, S_{y, x}, X_{1}, X_{2}, \ldots X_{N}\right)$. That error term must be evaluated. Standard DOE practice allows the determination of that error to be expressed as a confidence interval. That interval is usually a 95.0 percent confidence interval. Hence, each point on the regression surface contains a value and a specified percent confidence interval.

TABLE 6.-SIGNIFICANT TERMS IN THE \%AU REGRESSION

\begin{tabular}{|c|c|c|c|}
\hline Term & $\begin{array}{c}\text { Normalized } \\
\text { Coeff. }\end{array}$ & P-value & $\begin{array}{c}\% \\
\text { Significant }\end{array}$ \\
\hline Intercept & 26.820 & 0.0002 & 99.98 \\
\hline Bjet & -32.660 & 0.0012 & 99.88 \\
\hline WjetWaip & 44.360 & 0.0002 & 00.98 \\
\hline Pjet/Po & -32.838 & 0.0020 & 99.80 \\
\hline $\begin{array}{c}\text { Bjet* } \\
\text { WjetWaip }\end{array}$ & -30.588 & 0.0029 & 99.71 \\
\hline $\begin{array}{c}\text { Bjet* } \\
\text { Pjet/Po }\end{array}$ & 43.313 & 0.0005 & 99.95 \\
\hline $\begin{array}{c}\text { Bjet } \\
{ }^{*}\end{array}$ & 19.660 & 0.0913 & 91.87 \\
\hline $\begin{array}{c}\text { (Wjet/Waip) } \\
\text { (Wjet* }\end{array}$ & -32.160 & 0.0022 & 99.88 \\
\hline $\begin{array}{c}\text { Bjet } \\
\text { (WjetWaip) }\end{array}$ & 46.838 & 0.0003 & 99.97 \\
\hline
\end{tabular}

(a) Hybrid Micro-Vane Actuators

\begin{tabular}{|c|c|c|c|}
\hline Term & $\begin{array}{c}\text { Normalized } \\
\text { Coeff. }\end{array}$ & P-value & $\begin{array}{c}\% \\
\text { Significant }\end{array}$ \\
\hline Intercept & 18.854 & 0.0001 & 99.99 \\
\hline Bjet & -31.450 & 0.0006 & 99.94 \\
\hline & & & \\
\hline Pjet/Po & 16.850 & 0.0002 & 99.98 \\
\hline & & & 99.90 \\
\hline $\begin{array}{c}\text { Bjet* } \\
\text { Pjet/Po }\end{array}$ & -14.638 & 0.0010 & 99.03 \\
\hline $\begin{array}{c}\text { Bjet2 } \\
\text { Bjet* }\end{array}$ & 16.514 & 0.0097 & 99.72 \\
\hline (WjetWaip) $^{2}$ & -20.836 & 0.0028 & 98.66 \\
\hline (WjetWaip) $^{2}$ & 18.087 & 0.0234 & \\
\hline
\end{tabular}

(b) Hybrid Micro-Ramp Actuators

Shown in Figures 5 to 10 are the response surfaces for the percent augmentation parameter $(\% \mathrm{Au})$ for the hybrid micro-vane actuators and hybrid micro-ramp actuators. They have been organized according to both micro-device and factor interaction. For example, Figures 5 to 7 show the computed response surfaces for the hybrid micro-vane actuators organized to illustrate the Ajet $\mathbf{x}$ (Wjet/Waip) factor interaction, Figure 5, the Ajet $x(\mathrm{Pjet} / \mathrm{Po})$ factor interaction, Figure 6, and the (Pjet/Po) $\times(\mathrm{Wjet} / \mathrm{Waip})$ factor interaction, Figure 7. Likewise, Figures 8 to 10 illustrates the computed response surfaces for the hybrid micro-ramp actuators organized according to the same factor interactions. Therefore, the 


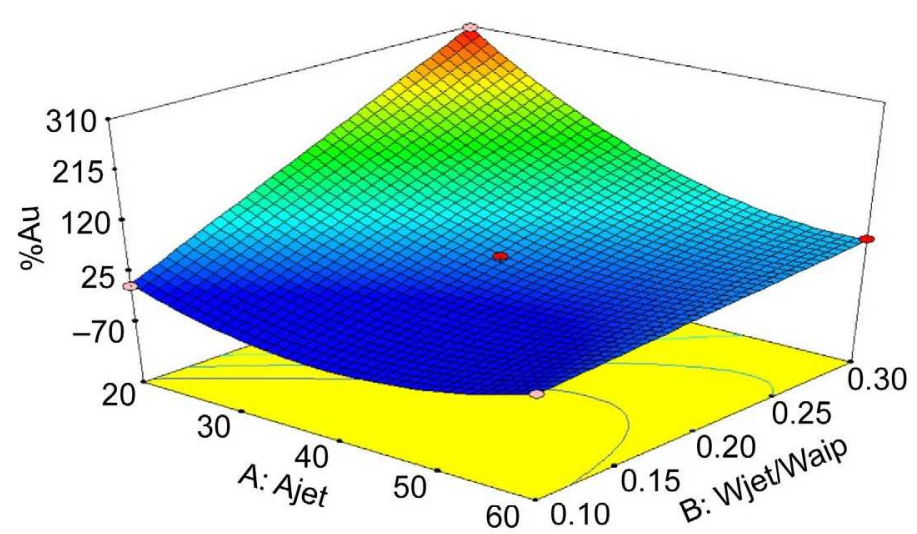

Figure 5.-Hybrid micro-vane percent \%Au response surface indicating Ajet x (Wjet/Waip) factor interaction.

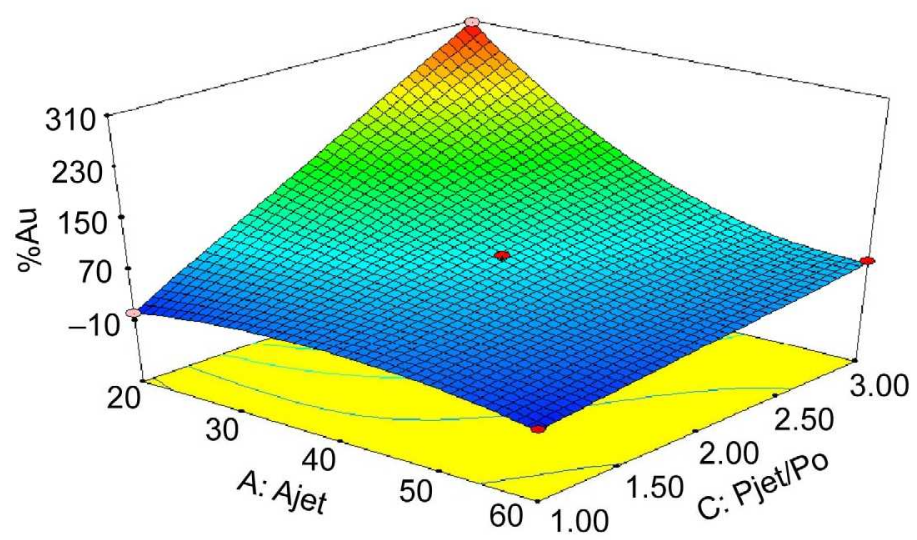

Figure 6.-Hybrid micro-vane percent \%Au response surface indicating Ajet x (Pjet/Po) factor interaction.

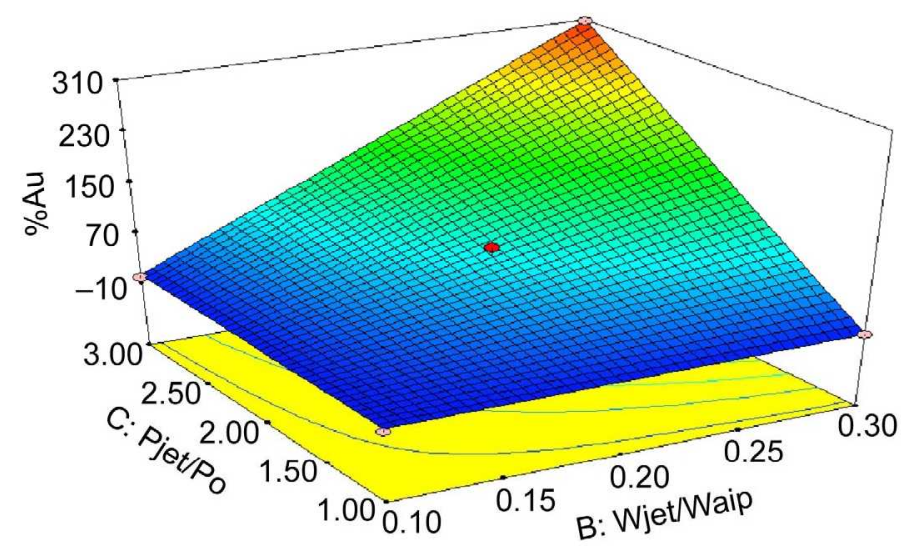

Figure 7.-Hybrid micro-vane percent \%Au response surface indicating $\mathrm{Pjet} / \mathrm{Po}) \times($ Wjet/Waip) factor interaction. 




Figure 8.-Hybrid micro-ramp percent \%Au response surface indicating Ajet $x$ (Wjet/Waip) factor interaction.

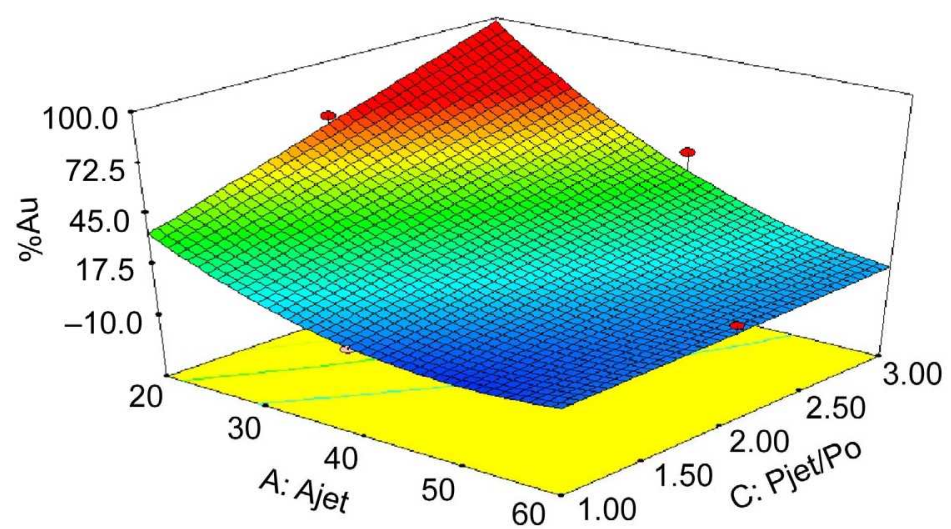

Figure 9.-Hybrid micro-ramp percent \%Au response surface indicating Ajet $\times(\mathrm{Pjet} / \mathrm{Po})$ factor interaction.

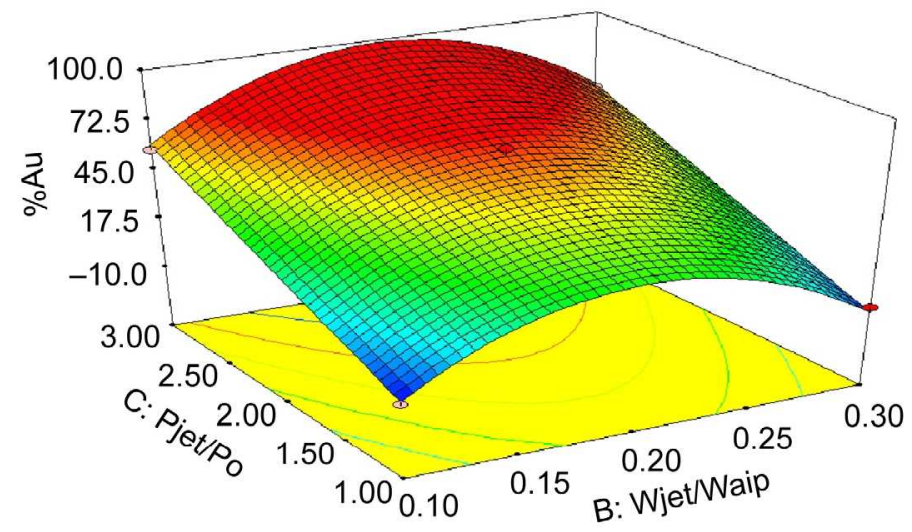

Figure 10.-Hybrid micro-ramp percent \%Au response surface indicating Pjet/Po) $\times($ Wjet/Waip) factor interaction. 
comparison of Figure 5 with Figure 8 illustrates the differences in the response surfaces for the hybrid micro-vane and hybrid micro-ramp actuators illustrated by the Ajet $\mathrm{x}$ (Wjet/Waip) factor interaction. One glaring feature of these response surfaces is the property that an optimum amount of injected mass flow exists beyond which the augmentation decreases. This is illustrated in Figures 8 and 10 for the hybrid micro-ramp actuator, where the optimal amount of injected mass flow (Wjet/Waip) is about 0.20 percent. There would probably be an optimal injected mass flow (Wjet/Waip) for the hybrid micro-vane actuator, since the same flow physics applies. (See section entitled "The Aerodynamic Properties of Optimal Hybrid Micro-Vane/Ramp Actuators". However, it was not demonstrated by this study).

Based on these response surfaces, the optimal hybrid micro-vane/ramp actuator configuration were established by maximizing the percent augmentation parameter (\%Au). The optimal results are listed in Table 7, and the 95.0 percent confidence interval associated with these optimal performance results is presented in Table 8. It is evident that the optimal hybrid micro-vane/ramp actuator can provide substantial augmentation of the control flow and that there is a range of micro-jet operating conditions where this augmentation is realized. Outside this useful operating range, the augmentation decreases very rapidly and can attenuate the micro-vane/ramp control flow. However, the 95.0 percent confidence interval on the optimal percent augmentation $(\% \mathrm{Au})$ is large. This confidence interval can be substantially reduced by a combination of three types of changes in the original DOE design layout. Consider the error term $\mathrm{Rn}\left(\mathrm{df}, \mathrm{S}_{\mathrm{y} . \mathrm{x}}, \mathrm{X}_{1}, \mathrm{X}_{2}, \ldots \mathrm{X}_{\mathrm{N}}\right)$ in Equation (4). The three combinations of changes are (1) centering the optimal micro-jet configuration in the original DOE design to decrease the distance between the optimal and the mean or centroid of the response data $\left(\mathrm{X}_{1}, \mathrm{X}_{2}, \ldots \mathrm{X}_{\mathrm{N}}\right),(2)$ reducing the factor range of the original DOE design to have more information in a smaller neighborhood of the optimal operating condition in order to reduce $S_{y \cdot x}$, and (3) increasing the number of CFD cases in the original DOE design to increase the degrees of freedom for the error (df).

TABLE 7.-OPTIMAL HYBRID MICRO VANE/ RAMP ACTUATOR CONFIGURATIONS

\begin{tabular}{|c|c|c|c|c|c|}
\hline Array & Bjet & Wjet/Waip & Pjet/Po & PFAVE & \%Au \\
\hline Micro-Vane & 20.0 & $0.30 \%$ & 3.0 & 0.967 & $307.1 \%$ \\
\hline Micro-Ramp & 20.0 & $0.20 \%$ & 3.0 & 0.968 & $98.3 \%$ \\
\hline
\end{tabular}

(1) Optimal based on maximizing \%Au

TABLE 8.-OPTIMAL HYBRID MICRO VANE/ RAMP ACTUATOR CONFIGURATIONS

\begin{tabular}{|c|c|c|c|c|c|c|}
\hline Array & PFAVE & $\begin{array}{c}-95.0 \\
\text { PFAVE }\end{array}$ & $\begin{array}{c}+95.0 \\
\text { PFAVE }\end{array}$ & $\%$ Au & $\begin{array}{c}-95.0 \\
\% A u\end{array}$ & $\begin{array}{c}+95.0 \\
\% A u\end{array}$ \\
\hline $\begin{array}{c}\text { Micro- } \\
\text { Vane }\end{array}$ & 0.967 & 0.966 & 0.968 & $307.1 \%$ & $240.0 \%$ & $371.0 \%$ \\
\hline $\begin{array}{c}\text { Micro- } \\
\text { Ramp }\end{array}$ & 0.968 & 0.966 & 0.971 & $98.3 \%$ & $65.3 \%$ & $131.1 \%$ \\
\hline
\end{tabular}

(1) Optimal based on maximizing \%Au

In order to further understand the interaction between the flow field induced by the micro-jet alone and that flow field induced by the integrated micro-vane/ramp actuators, three baseline micro-jet cases were run that simulated the CFD configurations srm201, srm207, and srm209 in Table 5. The purpose of these calculations was to determine the baseline augmentation produced by the isolated micro-jet as determined by Equation (5). The percent ratio of transverse to streamwise kinetic energy $(\% \mathrm{~K})$ was respectively, $0.006,0.256$, and 0.126 percent. The isolated baseline micro-jet augmentation for these same CFD cases was $0.1,4.0$, and 1.9 percent, and the comparable performance augmentations for the hybrid micro-ramp actuators are, respectively $-5.3,57.2$, and 71.0 percent. Therefore, one can not explain the 
high augmentation induced with the hybrid micro-vane/ramp actuators as a simple linear combination of micro-jet and micro-vane/ramp flow fields. It is the nonlinear interaction between the micro-jet and microvane/ramp that provides the design advantage of the "fail safe" hybrid micro vane/ramp actuators over simple micro-jet actuators.

The nonlinear nature of the transverse to stream-wise kinetic energy $(\% \mathrm{~K})$ and micro-jet augmentation $(\% \mathrm{Au})$ response variables follows from the linear relationship between the mean responses and the standard deviations of the responses, which indicates that the functional relationships of the response variables are exponential. It also was revealed by the large confidence intervals that were observed at the optimal design condition. Based on these results, a logarithm transformation of the response is appropriate and will stabilize the variation over the range of the response variable. While the DOE response surface for $(\% \mathrm{Au})$ is linear in the transformed plane, it is highly nonlinear in the untransformed plane. Hence, DOE has the ability to treat highly nonlinear aerodynamic problems. In fact, it is therefore possible to treat highly nonlinear aerodynamic problems with only a two level DOE factorial or fractional factorial design.

\section{The Aerodynamic Properties of Optimal Hybrid Micro-Vane/Ramp Actuators}

Presented in Figures 11 to 13 is a comparison between the baseline micro-vane/ramp flow field and the optimal hybrid micro-vane/ramp flow field. Figure 11 shows this comparison between the transverse Mach number contours at the reference (AIP) plane for the standard and hybrid micro-vane actuator. This comparison indicates that the effect of the optimal injected jet is to energize the near-wall boundary-layer region. Likewise, Figure 12 shows the same comparison of the transverse Mach number contours for the standard and hybrid micro-ramp actuator. It also shows that the impact of the optimal micro-jet on the vortex induced by the standard micro-ramp is to energize the near-wall boundary layer. The characteristic effect of energizing the near-wall boundary layer can also be seen in the comparison between the streamwise velocity profiles for the hybrid micro-ramp at the upwash and downwash regions of the induced micro-ramp vortex, Figure 13.

(a)



(b)



Figure 11.-Effect of hybrid micro-vane actuation on the Mach number contours at the AIP (reference) station. (a) Standard micro-vane actuator configuration. (b) Optimal hybrid micro-vane actuator configuration. 
(a)

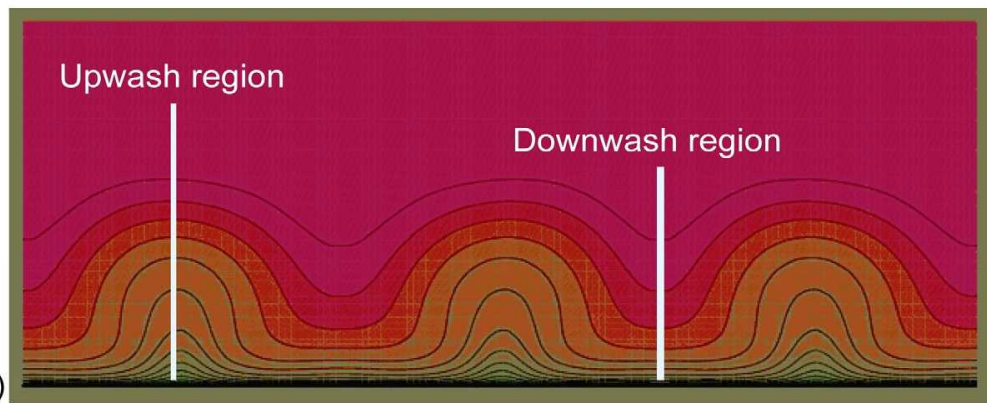

(b)



Figure 12.-Effect of hybrid micro-ramp actuation on the Mach number contours at the AIP (reference) station. (a) Standard micro-ramp actuator configuration. (b) Optimal hybrid micro-ramp actuator configuration.
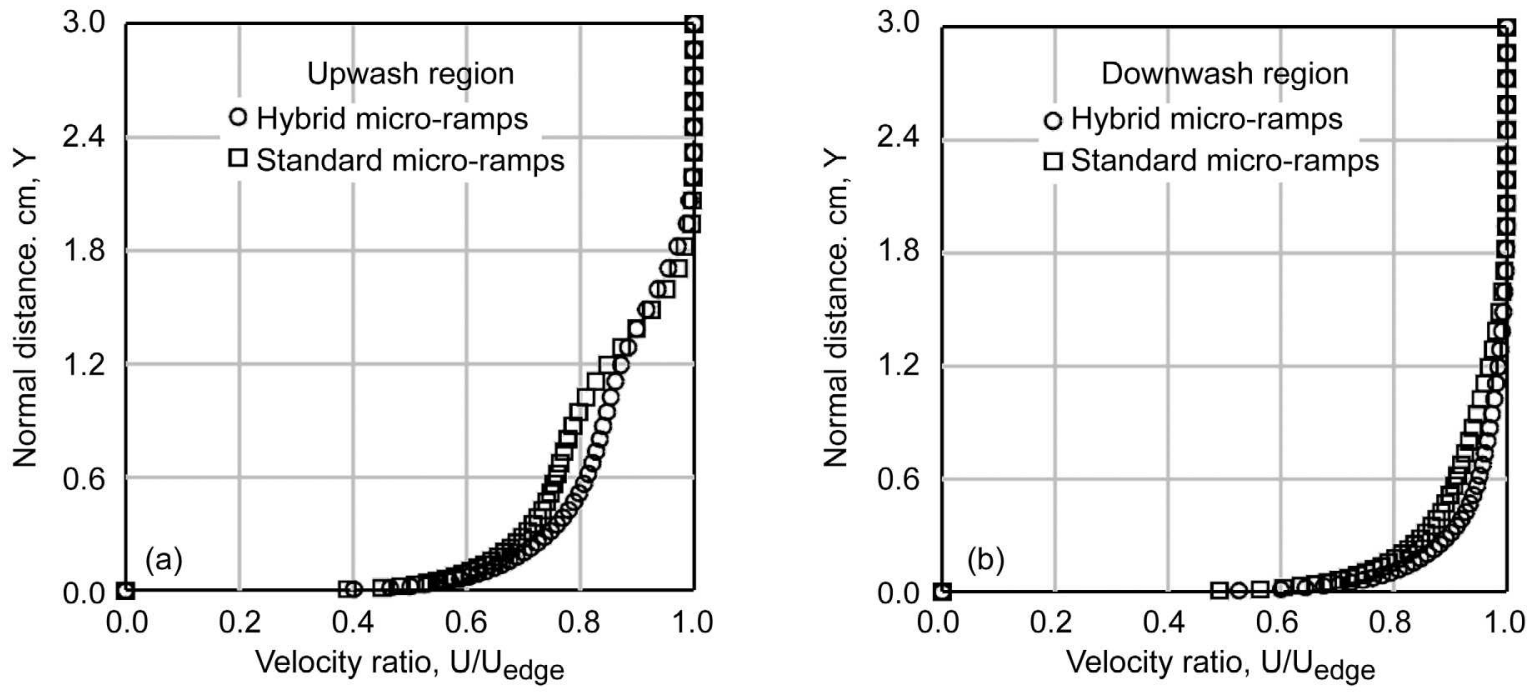

Figure 13.-Effect of hybrid micro-ramp actuation on the boundary layer velocity profiles at the AIP (reference) station. (a) Upwash region. (b) Downwash region.

The characteristic effect of optimal hybrid micro-vane/ramp actuators is therefore to energize the near wall boundary layer. This explains why an optimal relationship exists between the micro-jet and micro vane/ramp combination. A micro-jet operated at high pressure may only puncture into the outer portion of the boundary layer or the free stream and not energize the near wall boundary layer. A micro-jet operated a low pressure may not energize the near wall boundary layer. Because of the large number of independent factor (design) variables that will impact the relationship between the micro-jet and micro vane/ramp combination, it is very difficult to locate (define) an optimal configuration. Hence the need for Design-of-Experiments (DOE) methodology in this search for the optimal is evident. 


\section{Summary of Results}

The primary objective of this research effort was to develop and analytically demonstrate enhanced first generation active "fail-safe" hybrid flow-control techniques to simultaneously manage the boundary layer on the vehicle fore-body and to control the secondary flow generated within modern serpentine or embedded S-duct inlet configurations. The enhanced first-generation technique focused on both micro-vanes and micro-ramps highly-integrated with micro-jets to provide nonlinear augmentation for the "strength" or effectiveness of highly-integrated flow control systems. The study demonstrated using micro-jet operating in a mass flow ratio (Wjet/Waip) range from 0.10 to 0.30 percent and jet total pressure ratios (Pjet/Po) range from 1.0 to 3.0 can substantially augment the control flow. The needed engine bleed airflow range represents about a 10 fold decrease in micro-jet airflow than previously required for control. Therefore, by preconditioning, or injecting a very small amount of high-pressure jet flow into the vortex generated by the micro-vane and/or micro-ramp, "fail safe" active flow control was achieved and substantial augmentation of the controlling flow is realized.

\section{References}

1. Anderson, B.H., and Gibb, J., 1996, "Vortex Generation Installation Studies on Steady State and Dynamic Distortion," AIAA Paper No. 96-3279, 1996.

2. Anderson, B.H., Miller, D.M., Yagel, P.J, and Traux, P.P., "A Study of MEMS Flow Control for the Management of Engine Face Distortion in Compact Inlet Systems," FEDSM99-6920, 3rd ASME/JSME Joint Fluids Engineering Conference, San Francisco, CA, July 18-23, 1999.

3. Hamstra, J.W., Miller, D.N., Truax, P.P., Anderson, B.H., and Wendt, B.J., "Active Inlet Flow Control Technology Demonstration," ICAS-2000-6.11.2, 22nd International Congress of the Aeronautical Sciences, Harrogate, UK, August 27th-September 1st, 2000.

4. Anderson, B.H., and Keller, D., "A Robust Design Methodology for Optimal Micro-Scale Secondary Flow Control in Compact Inlet Diffusers," AIAA-2002-0541, 40th Aerospace Sciences Meeting and Exhibit, Reno, Nevada, January 14-17, 2002.

5. Anderson, B.H., Keller, D.J., "Optimal Micro-Scale Secondary Flow Control for the Management of High Cycle Fatigue and Distortion in Compact Inlet Diffusers," NASA/TM-2002-211686, July, 2002.

6. Anderson, B.H., Baust, H.D., and Agrell, J., "Design-of-Experiments to Reduce Life-Cycle Costs in Combat Aircraft Inlets," AIAA-2003-0652, 41st Aerospace Sciences Meeting and Exhibit, Reno, Nevada, January 6-9, 2003.

7. Anderson, B.H., Miller, D.N., Gridley, M.C., and Agrell, J., "The Role of Design-of-Experiments in Managing Flow in Compact Air Vehicle Inlets," NASA/TM-2003-212601, Prepared for the Vehicle Propulsion Integration Symposium, NATO Research and Technology Agency, Warsaw, Poland, Oct. 6-9, 2003.

8. Anderson, B.H., Tinapple, J., and Surber, L. "Optimal Control of Shock Wave Turbulent Boundary Layer Interactions Using Micro-Array Actuation," AIAA-2006-3197, June, 2006.

9. Box, G.E.P., Hunter, W.G., and Hunter, J.S., "Statistics for Experimenters," John Wiley, New York.

10. Taguchi, G. and Wu, Y., "Introduction to Off-Line Quality Control," Central Quality Control Association, 1980.

11. NPARC Alliance, "The Wind-US Code," http://www/grc.nasa/www/Wind-US_docs [cited 13 June 2004.

12. Bush, R.H., Power, G.D., and Towne, C.E., "Wind-US: The Production Flow Solver of the NPRAC Alliance," AIAA-1998-0935, January 1998. 


\begin{tabular}{|c|c|c|c|c|c|}
\hline \multicolumn{5}{|c|}{ REPORT DOCUMENTATION PAGE } & $\begin{array}{c}\text { Form Approved } \\
\text { OMB No. 0704-0188 }\end{array}$ \\
\hline \multicolumn{6}{|c|}{  } \\
\hline \multicolumn{2}{|c|}{$\begin{array}{l}\text { 1. REPORT DATE (DD-MM-YYYY) } \\
01-08-2009\end{array}$} & \multicolumn{3}{|c|}{$\begin{array}{l}\text { 2. REPORT TYPE } \\
\text { Technical Memorandum }\end{array}$} & 3. DATES COVERED (From - To) \\
\hline \multirow{3}{*}{\multicolumn{5}{|c|}{$\begin{array}{l}\text { 4. TITLE AND SUBTITLE } \\
\text { Active "Fail-Safe" Micro-Array Flow Control for Advanced Embedded Propulsion Systems }\end{array}$}} & 5a. CONTRACT NUMBER \\
\hline & & & & & 5b. GRANT NUMBER \\
\hline & & & & & 5c. PROGRAM ELEMENT NUMBER \\
\hline \multirow{3}{*}{\multicolumn{5}{|c|}{$\begin{array}{l}\text { 6. AUTHOR(S) } \\
\text { Anderson, Bernhard, H.; Mace, James, L.; Mani, Mori }\end{array}$}} & 5d. PROJECT NUMBER \\
\hline & & & & & 5e. TASK NUMBER \\
\hline & & & & & $\begin{array}{l}\text { 5f. WORK UNIT NUMBER } \\
\text { WBS 984754.02.07.03.13.02 }\end{array}$ \\
\hline \multicolumn{5}{|c|}{$\begin{array}{l}\text { 7. PERFORMING ORGANIZATION NAME(S) AND ADDRESS(ES) } \\
\text { National Aeronautics and Space Administration } \\
\text { John H. Glenn Research Center at Lewis Field } \\
\text { Cleveland, Ohio 44135-3191 }\end{array}$} & $\begin{array}{l}\text { 8. PERFORMING ORGANIZATION } \\
\text { REPORT NUMBER } \\
\text { E-16887 }\end{array}$ \\
\hline \multirow{2}{*}{\multicolumn{5}{|c|}{$\begin{array}{l}\text { 9. SPONSORING/MONITORING AGENCY NAME(S) AND ADDRESS(ES) } \\
\text { National Aeronautics and Space Administration } \\
\text { Washington, DC 20546-0001 }\end{array}$}} & $\begin{array}{l}\text { 10. SPONSORING/MONITOR'S } \\
\text { ACRONYM(S) } \\
\text { NASA; AIAA }\end{array}$ \\
\hline & & & & & $\begin{array}{l}\text { 11. SPONSORING/MONITORING } \\
\text { REPORT NUMBER } \\
\text { NASA/TM-2009-215596; AIAA-2009- } \\
0741\end{array}$ \\
\hline \multicolumn{6}{|c|}{$\begin{array}{l}\text { 12. DISTRIBUTION/AVAILABILITY STATEMENT } \\
\text { Unclassified-Unlimited } \\
\text { Subject Category: } 07 \\
\text { Available electronically at http://gltrs.grc.nasa.gov } \\
\text { This publication is available from the NASA Center for AeroSpace Information, } 443-757-5802\end{array}$} \\
\hline \multicolumn{6}{|c|}{ 13. SUPPLEMENTARY NOTES } \\
\hline \multicolumn{6}{|c|}{$\begin{array}{l}\text { 14. ABSTRACT } \\
\text { The primary objective of this research effort was to develop and analytically demonstrate enhanced first generation active "fail-safe" hybrid } \\
\text { flow-control techniques to simultaneously manage the boundary layer on the vehicle fore-body and to control the secondary flow generated } \\
\text { within modern serpentine or embedded inlet S-duct configurations. The enhanced first-generation technique focused on both micro-vanes } \\
\text { and micro-ramps highly-integrated with micro-jets to provide nonlinear augmentation for the "strength" or effectiveness of highly-integrated } \\
\text { flow control systems. The study focused on the micro-jet mass flow ratio (Wjet/Waip) range from } 0.10 \text { to } 0.30 \text { percent and jet total pressure } \\
\text { ratios (Pjet/Po) from } 1.0 \text { to } 3.0 \text {. The engine bleed airflow range under study represents about a } 10 \text { fold decrease in micro-jet airflow than } \\
\text { previously required. Therefore, by pre-conditioning, or injecting a very small amount of high-pressure jet flow into the vortex generated by } \\
\text { the micro-vane and/or micro-ramp, active flow control is achieved and substantial augmentation of the controlling flow is realized. } \\
\text { 15. SUBJECT TERMS } \\
\text { Aerodynamics; Propulsion; Fluid dynamics }\end{array}$} \\
\hline \multicolumn{3}{|c|}{ 16. SECURITY CLASSIFICATION OF: } & $\begin{array}{l}\text { 17. LIMITATION OF } \\
\text { ABSTRACT }\end{array}$ & $\begin{array}{l}\text { 18. NUMBER } \\
\text { OF }\end{array}$ & $\begin{array}{l}\text { 19a. NAME OF RESPONSIBLE PERSON } \\
\text { STI Help Desk (email:help@sti.nasa.gov) }\end{array}$ \\
\hline $\begin{array}{l}\text { a. REPORT } \\
\text { U }\end{array}$ & $\begin{array}{l}\text { b. ABSTRACT } \\
\text { U }\end{array}$ & $\begin{array}{l}\text { c. THIS } \\
\text { PAGE } \\
\text { U }\end{array}$ & UU & $\begin{array}{l}\text { PAGES } \\
21\end{array}$ & $\begin{array}{l}\text { 19b. TELEPHONE NUMBER (Include area code) } \\
\text { 443-757-5802 }\end{array}$ \\
\hline
\end{tabular}



